\title{
Quelques pistes pour aborder la culture en classe de FLE ${ }^{1}$
}

\section{(Enfoques para abordar la cultura en la clase de FLE)}

\author{
Julio Sánchez Murillo² \\ Universidad Nacional, Costa Rica \\ Gredy Sibaja \\ Hernández ${ }^{3}$ Universidad
}

Nacional, Costa Rica

\section{résumé}

De nos jours, la culture occupe une place importante dans les programmes et cours de langues étrangères, c'est pourquoi il s'avère pertinent d'aborder quelques aspects liés à l'enseignement de la culture en classe de FLE. Dans cet article, on analyse la notion de culture, le rôle du professeur dans le processus d'apprentissage de celle-ci et on propose une révision succincte des différentes approches pour traiter les faits culturels en classe. En outre, on présente quelques suggestions concernant les contenus et les supports visant à construire une démarche cohérente d'étude de la cultureétrangère.

\section{resumen}

La cultura sigue ocupando un lugar importante en los programas y cursos de lenguas extranjeras. Por ello, conviene analizar aspectos relacionados con la enseñanza de la cultura en la clase de francés. En este artículo, se examina el término cultura, el papel del profesor en el proceso de aprendizaje de ésta y se propone una revisión sucinta de los diferentes enfoques para tratar los hechos culturales en la clase. Además, se plantean propuestas

1 Recibido: 23 de setiembre de 2012; aceptado: 5 de febrero de 2013.

2 Escuela de Literatura y Ciencias del Lenguaje; correo electrónico: jesm80@ costarricense.cr

3 Escuela de Literatura y Ciencias del Lenguaje; correo electrónico: gashfrancais@yahoo.fr 
sobre los contenidos y tipos de documentos con el objetivo de construir un modelo coherente de estudio de la cultura extranjera.

Mots clés : enseignement de la culture, culture, approche interculturelle, enseignement de langues, langue française

Palabras clave: enseñanza de la cultura, cultura, enfoque intercultural, enseñanza de lenguas, lengua francesa

"L'apprentissage de la langue étrangère selon le modèle interculturel se fait dans le contexte des relations humaines, de découverte de soi, de l'autre et de la pluralité des identités culturelles. »

Ross Steele

Depuis des lustres, la culture fait partie indispensable des programmes de l'enseignement-apprentissage du français langue étrangère (FLE). Toutefois, sa place a varié tout au long des années. Elle a laissé d'être tributaire, on le suppose, de la «mission civilisatrice » de la France, selon une vision classique, ainsi que de l'apprentissage de la langue ou de la littérature françaises et elle est devenue un objectif en soi et son étude s'est institutionnalisée dans les salles de cours de français.

L'évolution de la place de cette discipline, dans le cadre du FLE, a pris des années. L'enseignement de la culture a débuté, au Moyen-âge et pour arriver à son état actuel, le plus proche de l'idéal ; il a dû subir des changements et s'adapter aux exigences de l'époque, des enseignants et, notamment, des apprenants. En ce qui concerne ces transformations, on peut remarquer une évolution des supports à utiliser pour développer l'étude de l'autre, des contenus proposant une approche de la réalité de l'étranger moins livresque et plus proche de la quotidienneté de celui-ci et, principalement, les objectifs de l'enseignement de la culture ; à nos jours, il s'agit de connaître mais surtout, decomprendre l'autre.

Malgré ce qu'on vient de mentionner, l'enseignement de la culture ne termine pas de poser des défis aux enseignants de FLE, particulièrement dans le milieu costaricien, caractérisé par l'absence 
de contact fréquent avec des Francophones et le vide existant concernant le quoi et le comment enseigner.

Ces éléments ne sont pas les seuls à empêcher une vraie étude de la culture cible. L'approche mise en pratique, dans la plupart des cas ne dépasse pas le niveau descriptif et comparatif, qui n'est pas négligeable et reste encore intéressant ; cependant, il faudrait favoriser un enseignement qui facilite l'analyse qui mène à la compréhension d'autrui et à une réflexion sur la culture maternelle.

Pour atteindre ces objectifs et mener à bien le processus d'enseignement-apprentissage de la culture autre, il est nécessaire de réfléchir à propos de divers aspects théoriques, des éléments essentiels permettant une étude appropriée de l'autre. Parmi ces aspects fondamentaux, on doit mentionner la notion de culture et l'approche interculturelle.

\section{Notion(s) de culture}

À présent, on est d'accord qu'il existe un lien étroit entre l'étude de langue et celle de la culture, et que son étude est devenue un point primordial dans l'enseignement des langues étrangères. Il est donc important d'analyser certains aspects qui entourent la notion de culture. Cependant, avant d'établir une réflexion sur ces points, il faut faire référence à une situation existante depuis des décennies : les divergences suscitées entre les spécialistes en didactique de cultures en ce qui concerne l'utilisation du concept civilisation ou celui de culture.

Leterme civilisation afait son apparition dans les programmes de FLE au xix siècle, il faut remarquer que ce terme a été employé pour la première fois par le marquis de Mirabeau au xviii ${ }^{\mathrm{e}}$ siècle :

À bon droit les Ministres de la Religion ont-ils les premiers rangs dans une Société bien ordonnée. La Religion est sans contredit le premier et le plus utile frein de l'humanité, c'est le premier ressort de la civilisation $[\ldots]^{4}$ 
Plus tard, Mirabeau ${ }^{5}$ associe ce mot aux sociétés les plus avancées et on ne doit pas oublier que cette conception du terme civilisation a été utilisée par les sociétés auto-nommées «évoluées » (les sociétés européennes) pour entreprendre un processus qui permettrait aux sociétés des autres régions, hors l'Europe occidentale (dénommées à l'époque comme barbares et sauvages) de s'approcher de leur civilisation. De cette façon, ces sociétés européennes ont essayé d'imposer leur vision du monde en mettant en relief leur prOGrès scientifique et technique, leur production artistique et leur mode de vie aux groupes sociaux habitant les pays qui sont devenus des colonies européennes au fur et à mesure que les xviii et ${ }^{\mathrm{e}}{ }^{\mathrm{e}}{ }^{\mathrm{e}}$ siècles passaient. Tout cela au nom de «la progression de l'humanité. »

Même si, ces idées se sont reproduites tout au long de l'histoire ; voire après la fin des empires coloniaux ; un changement s'est aussi suscité dans la conception établie par Mirabeau et désormais, lorsqu'on parlerait de civilisation, on ferait allusion au sens que l'historien François Guizot (1838) a accordé à ce mot : «Ensemble de caractères propres à une société quelconque ». ${ }^{6} \mathrm{Ce}$ sens dénote « une volonté de considérer toutes les sociétés humaines, dans le temps et dans l'espace, avec un égal intérêt, chacune comme un sujet d'étude à part entière $»^{7}$

En dépit d'une évolution à propos de la définition, d'autres problèmes ont surgi avec cette nouvelle conception ; on ne s'est pas mis d'accord en ce qui concerne les caractères qui devraient être pris en considération lors de définir une civilisation quelconque ; en plus, des spécialistes se sont questionnés sur l'impossibilité de présenter une civilisation comme un ensemble cohérent et homogène. On a essayé d'éclaircir ces questionnements en proposant une analyse de cette notion à partir des réalités d'une civilisation, des manifestations de celle-ci et d'un système qui pourrait se dégager de ces manifestations.

5 M. Tabuce, Atelier de sciences du langage [En ligne]http://asl.univ-montp3.fr/e22mcb/ E22BCM-1-2.pdf, page consultée le 20 mars 2013.

6 Dictionnaire Le Grand Larousse de la langue française (Paris : Larousse, 1969) 750.

7 M. B. Le Berre, Compétence culturelle et didactiques des cultures (Poitiers : CNED, 1992) 14. 
Toutefois, d'autres problèmes ont été exposés ; par exemple, quel serait le niveau d'analyse dans lequel on doit se situer dans l'étude d'une société et quels seraient les éléments nécessaires pour démontrer qu'un caractère donné est propre à une société déterminée.

De nouvelles idées, pour élucider ces questionnements, sont apparues au cours du $\mathrm{xx}^{\mathrm{e}}$ siècle. Néanmoins, elles ne feraient plus référence au terme civilisation mais à celui de culture puisque l'influence de l'ethnologie anglo-saxonne a poussé l'utilisation de ce concept au détriment de civilisation ; dans certains pays, il est de plus en plus employé comme un équivalent de culture ; par exemple : des spécialistes et des auteurs de manuels.

L'emploi du terme culture dans l'enseignement de langues étrangères s'appuie sur un cadre conceptuel soutenu par différentes sciences sociales, mais principalement par la sociolinguistique et l'anthropologie, auxquelles on a fait appel lors du renouveau de l'enseignement de la culture. Pourtant, son usage de ce terme n'est pas exempt de polémique ; depuis longtemps, on a essayé de définir ce mot, plusieurs notions proposées ont été accusées d'incomplètes ou réductrices, ou simplement, d'être une continuation du terme civilisation ou de faire partie de celle-ci. En dépit de ces complications, les efforts poursuivis jusqu'à maintenant pour donner une définition de culture sont remarquables.

À ce point, il est pertinent de faire référence à quelques définitions de culture conçues depuis les années 1960. Parmi les travaux les plus notables quant à la conception de ce mot-ci, considéré par certains comme un mot piège, on peut citer, pour commencer, l'intellectuel britannique Raymond Williams (1965), il construit une notion de culture à partir de trois grandes catégories :

Il existe trois grandes catégories dans la définition de la culture. Tout d'abord, le domaine de « idéal » de certaines valeurs universelles, dans lequel la culture est un état de perfection humaine ou un processus y conduisant. Ensuite, il y a le domaine «documentaire » dans lequel la culture constitue l'ensemble des productions 
intellectuelles et créatives, et dans lequel se trouvent dans le détail la pensée et l'expérience humaine. L'analyse de la culture définie ainsi constitue l'activité de la critique. Enfin, il existe une définition « sociale » du terme, qui fait de la culture la description d'un mode de vie particulier traduisant certaines significations et certaines valeurs non seulement dans le monde de l'art ou du savoir, mais aussi dans les institutions et le comportement habituel. ${ }^{8}$

Ces catégories, sur lesquelles R. Williams propose sa notion de culture, à savoir, l'idéal, le documentaire et le social nous mènent à poser quelques questions ; par exemple, quelles seraient ces valeurs universelles qui composent l'idéal ? Ces valeurs dénommées universelles sont-elles partagées par toutes les sociétés?

Un autre point qui semble un peu compliqué à saisir, c'est l'idée de culture comme « un état de perfection humaine ou un processus y conduisant $»$; car c'est trop utopique, étant donné la reconnue imperfection de l'être humain.

La deuxième catégorie appelée « documentaire » fait référence à la production notamment artistique d'une société, comme des expressions de la pensée et l'expérience d'un groupe social. Cette dernière idée semble très intéressante et appropriée car cette notion les présente, même si elles ne sont pas les seules, comme des manifestations de la pensée et de l'expérience humaine, par conséquent d'un groupe social déterminé ; et d'après cette conception, ces productions ne sont plus le résultat de l'inspiration et la créativité individuelles et prennent la valeur des expressions, en général, détaillées d'une société.

La dernière composante de la notion proposée par Williams est plus proche du sens anthropologique de culture prôné dans les dernières années. Précisément, de cette dernière idée se dégage la conception de culture de l'anthropologue E. Leach (1982) ${ }^{9}$. D'après lui, il existe des éléments particuliers, qu'il appelle « attributs culturels propres », qui caractérisent les sociétés qui sont, à la fois, déterminées par des unités politiques, démarquées territorialement. Parmi ces éléments, on peut 8 R. Williams, cité par M. Byram, (Culture et éducation en langue étrangère, Paris : Hatier/Didier, 1992) 111.

9 E. Leach, cité par M. Byram, Culture et éducation en langue étrangère (Paris : Hatier/Didier, 1992) 112. 
citer ; les images linguistiques, les mœurs, la nourriture et l'habitat ; étant, selon lui, définis par la stratification sociale. En plus, ceux-ci établissent ce que Leach nomme la «différenciation culturelle. »

Des aspects remarquables déterminent la conception de E.

Leach tels que les traits particuliers d'un groupe social dans une culture et qui la différencient des autres appartenant à la même culture. Ces différences enracinées entre les divers groupes sociaux sont surtout perçues par des observateurs qui sont hors cette réalité. Williams et Leach considèrent la culture comme une «ex- pression de significations »; Leach remarque que « les artefacts qui servent souvent de symboles de signification peuvent être utilisés de manière différente par les diverses parties d'une société et que leur usage n'est pas quelque chose de fixe et de stable. $\rangle^{10}$

Dans cette même perspective, on a commencé à voir la culture comme un système de croyances, de valeurs ainsi que de significations ; d'après ceci, une étude de la culture à partir de l'observation des idées serait pertinente et on laisserait de côté l'observation et la description des attitudes. Cette proposition était déjà très répandue dans le domaine des sciences sociales ce qui est témoigné par l'anthropologue étatsunien W. Goodenough (1964) dans sa définition de culture:

La culture d'une société est constituée de tout ce que l'on a à connaître ou à croire pour se comporter de façon acceptable aux yeux des individus qui en font partie. La culture n'est pas un phénomène naturel : elle n'est pas faite de choses, de comportements ou d'émotions. C'est bien plutôt une façon d'organiser ces éléments. C'est la forme des choses que les gens ont dans la tête, leurs modèles de perception, de mise en relation et d'interprétation de ces éléments mentaux. ${ }^{11}$

D'après cette notion, ce qui intéresse ce ne sont ni les choses, ni les comportements ni les émotions, supposés comme des éléments qui font une culture ; c'est-à-dire, les productions matérielles qu'on

10 Leach, 112.

11 W. H. Goodenough, cité par M. Byram, Culture et éducation en langue étrangère (Paris : Hatier/ Didier, 1992) 113. 
présume que ce dont parle Goodenough comme choses ; les modes d'agir, nommés par lui comportements et les émotions que l'on pourrait lier au côté psychologique ou spirituel, ne sont pas vraiment le plus important dans l'étude d'une culture car, pour Goodenough, la manière d'organiser ces éléments par les membres d'un groupe social déterminé ainsi que la forme, la perception, la relation et l'interprétation que les gens ont de ces éléments est le plus significatif.

D'autre part, pour certains spécialistes, la culture est conçue comme un savoir, mais un savoir «partagé » et «négocié » par tous les individus d'un groupe social. La conception de culture de l'anthropologue Clifford Geertz, en 1975, met en relief le caractère systématique et héritable de ce savoir. Selon lui, la culture est :

Une structure -transmise historiquement- de significations incarnées dans des symboles, un système d'idées héritées et exprimées sous forme symbolique, au moyen desquelles les hommes communiquent, perpétuent et étendent leur savoir concernant les attitudes envers la vie. ${ }^{12}$

Ce savoir se manifeste dans des comportements et des « artefacts » de même que dans l'articulation de règles, normes, codes moraux, proverbes, etc. Dans la plupart des cas, ces marques culturelles sont transmises, généralement des parents aux enfants de manière implicite, spontanée et inconsciente.

Les significations auxquelles se réfere Geertz existent dans la réalité sociale et intègrent les pratiques culturelles de cette réalité. Pour C. Taylor $(1971)^{13}$, ces significations existent dans l'esprit des membres d'un groupe quelconque aussi bien que dans les pratiques qui sont fondamentalement des formes de relation sociale et d'actions réciproques. Dans cette structure de significations culturelles, selon Geertz, vivent les individus ; et dans tout groupe d'individus, il existe,

12 C. Geertz, cité par M. Byram, Culture et éducation en langue étrangère (Paris : Hatier/Didier, 1992) 113.

13 C. Taylor, cité par M. Byram, Culture et éducation en langue étrangère (Paris : Hatier/Didier, 1992) 113. 
d'après Taylor, des « significations communes » que chaque individu possède et qui font partie du monde de références communes. Pour lui, ces significations sont la base de la communauté et il ajoute :

Les significations intersubjectives donnent à un peuple une langue commune pour parler de la réalité sociale, et une compréhension commune de certaines normes, mais ce n'est qu'avec des significations communes que ce mode de références communes peut comporter des actions communes, des célébrations et des sentiments significatifs. Ce sont les objets du monde que tous partagent, ce qui crée une communauté. ${ }^{14}$

Parmi les types de significations communes, Taylor ${ }^{15}$ en distingue trois, à savoir:

- des règles constitutives : des normes qui montrent la façon dont les membres d'un groupe social se mettent d'accord sur des significations partagées.

- des artefacts : des produits et des symboles d'actions reconnues et acceptées par tous, qui possèdent une signification et sont eux-mêmes investis d'une signification. On trouve deux types d'artefacts ; ceux qui appartiennent au monde physique comme les formes artistiques traditionnelles, les styles vestimentaires ou culinaires ainsi que les productions littéraires, musicales et d'autres. Ces artefacts sont remplis des significations culturelles. Il existe une classe de significations dans la réalité sociale à propos desquelles les individus ressentent un sens de la communauté, celles-ci sont des artefacts primordiaux dans une culture déterminée.

- des institutions sociales : elles sont décrites comme des comportements observables, porteurs de significations culturelles. Cette 
portée culturelle s'explicite quand les idées construites par les individus par rapport à la signification d'une institution sociale donnée, sont formulées en termes de règles constitutives.

Il est important de remarquer que, dans le cadre de l'enseignement de langues étrangères, la description des comportements, des artefacts et des institutions est valable mais insuffisante. Il est indispensable de faire découvrir la portée culturelle de ceux-ci.

Tout au long des années, d'autres spécialistes ont formulé des définitions de culture. Ces définitions se situent, chacune avec leurs propres nuances, dans le même sens de celles qu'on a déjà citées et commentées. Parmi ces notions, on n'en voudrait évoquer que trois, qui semblent très pertinentes et qui ont, bien sûr, contribué à la définition de culture, qui n'est pas de tout point de vue une tâche facile.

Voyons, alors, ces définitions, l'anthropologue Clyde Kluckhohn définit, en 1966, culture comme :

L'ensemble de modes de vie d'un peuple, l'héritage social que l'individu acquiert de son groupe. En d'autre mode, la culture est cette partie de son milieu que l'homme a lui-même créé. ${ }^{16}$

Cette définition présente des coïncidences avec les précédentes. Comme Williams et Leach, Kluckhohn remarque l'importance des modes de vie d'un peuple comme élément constitutif de la culture car, comme il est évident, ceux-ci incarnent des significations culturelles et sont porteurs de valeurs communes à un groupe social donné. Un autre point de similitude, c'est la qualité d'héritabilité de la culture, c'est-à-dire, d'être transmise d'une génération à l'autre, dans ce cas la coïncidence est avec Geertz. De même que Taylor, Kluckhohn affirme que la vie en communauté favorise l'acquisition de cet héritage social constitué par les significations communes. En plus, il y a un élément qu'il mentionne et qui a été déjà cité plusieurs

16 C. Kluckhohn, cité par J. C. Beacco et S. Lieutaud, Mœurs et mythes (Paris: Hachette, 1981)8. 
fois par égal nombre de spécialistes, mais qui est toujours important de ne pas oublier, c'est le fait que la culture est une création de l'homme et non comme certains le croient, un élément naturel.

Une notion de culture citée un peu partout est celle de l'anthropologue et linguiste Edward Sapir (1967 dans l'édition française) qui considère la culture comme :

L'ensemble des attitudes, des visions du monde et des traits spécifiques de civilisation qui confère à un peuple particulier sa place originale dans l'univers. Ce qu'une société fait et pense. ${ }^{17}$

Cette proposition de culture, présente des ressemblances avec celles qu'on a mentionnées plus haut. Cependant, il est à remarquer le fait qu'elle montre celle-ci comme un élément faisant partie de la civilisation. On se demande, alors, quelle est la conception de civilisation de Sapir, pour quelles raisons la culture n'est pas indépendante de son point de vue et quelles sont ces caractéristiques particulières qui composent une civilisation.

D'autre part, Melville Jean Herskovits (1967) affirme que : « la culture se manifeste dans des institutions, des formes de pensée et des objets matériels. $\gg^{18}$ Comme Taylor, Herskovits conçoit la culture comme une manifestation dans trois états différents, dans les institutions sociales, dans les façons de penser et des objets matériels, ces derniers aspects sont liés à ce que Taylor a appelé, les artefacts.

Pour conclure, on voudrait présenter la notion de culture proposée par le linguiste français Robert Galisson: « la culture renvoie d'une part au culturel, d'autre part au cultivé $\gg{ }^{19} \mathrm{Il}$ est évident que cette notion présente la culture divisée en deux parties bien différenciées. Le culturel

17 E. Sapir, cité par C. Puren, «Interculturalité et interdidacticité dans la relation enseignementapprentissage en didactique des langues-cultures »,Études de Linguistique Appliquée 140 (SaintEtienne : CEDICLEC, Université de Saint-Étienne, 2005) 492.

18 M. J. Herskovits, cité par J.C. Beacco et S. Lieutad, Mours et Mythes (Paris : Hachette, 1979)8.

19 R. Galisson, «La culture partagée : une monnaie d'échange interculturelle », Dialogues et culture 32 (Paris : FIPF, 1988) 83. 
évoque ce qu'on connaît comme la culture quotidienne, particulièrement ce qui concerne les comportements d'un groupe social donné, et le cultivé ce que certains appellent la culture savante, tout ce qui se rapporte à la littérature, l'histoire, l'architecture, la musique, etc. Malgré la dissemblance évidente entre celles-ci, il existe une complémentarité entre elles : « le culturel est le passage obligé du cultivé. ${ }^{20}$ Cela nous permet d'affirmer qu'une ample étude d'une culture devrait, logiquement, comprendre les deux aspects qui, selon Galisson, conforment celle-ci vu qu'un d'eux permet une meilleure analyse et compréhension de l'autre.

Ce panorama nous a montré que la tâche de définir la culture n'est pas du tout facile. À continuation, on propose un tableau à manière de résumé, mais aussi dans le but de, d'abord, constater les difficultés dont on a déjà parlé, de définir ce mot ; après, d'établir des rapports de comparaison entre les diverses notions de culture et finalement, pour faire remarquer l'évolution, si elle existe, dans les conceptions de celle-ci.

\section{Tableau résumé des notionps de culture}

\begin{tabular}{|c|c|c|c|}
\hline Auteur & Définition & Comprenant & Relatif à \\
\hline $\begin{array}{l}\text { W. } \\
\text { Goodenough } \\
(1964)\end{array}$ & Constitution & $\begin{array}{l}\text { Une façon d'organiser les choses, } \\
\text { les comportements ou les émotions }\end{array}$ & une société \\
\hline $\begin{array}{l}\text { R. Williams } \\
\text { (1965) }\end{array}$ & $\begin{array}{l}\text { Trois grandes } \\
\text { catégories }\end{array}$ & $\begin{array}{l}\text { ○ l'idéal } \longrightarrow \text { valeurs universelles } \\
\text { ○ le documentaire } \longrightarrow \text { productions } \\
\text { intellectuelles et créatives } \\
\text { ○ le social } \longrightarrow \text { modes de vie }\end{array}$ & \\
\hline $\begin{array}{l}\text { C. Kluckhohn } \\
\text { (1966) }\end{array}$ & Ensemble & $\begin{array}{l}\text { Des modes de vie d'un peuple (héritage } \\
\text { social) }\end{array}$ & $\begin{array}{l}\text { un groupe } \\
\text { social }\end{array}$ \\
\hline
\end{tabular}

20 Galisson, 83. 


\begin{tabular}{|c|c|c|c|}
\hline $\begin{array}{l}\text { E. Sapir } \\
\text { (1967) }\end{array}$ & Ensemble & $\begin{array}{ll}\circ & \text { des attitudes } \\
\circ & \text { des visions du monde } \\
\circ & \text { des traits spécifiques }\end{array}$ & $\begin{array}{l}\text { un peuple } \\
\text { particulier }\end{array}$ \\
\hline $\begin{array}{c}\text { M.J. } \\
\text { Herskovits } \\
\text { (1967) }\end{array}$ & Manifestation & $\begin{array}{ll} & \text { des institutions } \\
\circ & \text { des formes de penser } \\
\circ & \text { des objets matériels } \\
\end{array}$ & \\
\hline $\begin{array}{l}\text { C. Geertz } \\
(1975)\end{array}$ & $\begin{array}{l}\text { Une structure } \\
\text { Un système }\end{array}$ & $\begin{array}{l}\text { des significations transmises dans des } \\
\text { des idées héritées et exprimées symbol }\end{array}$ & $\begin{array}{l}\text { mboles } \\
\text { uement }\end{array}$ \\
\hline $\begin{array}{l}\text { R. Galisson } \\
\text { (1988) }\end{array}$ & Deux parties & $\begin{array}{l}\text { ○ le culturel } \longrightarrow \text { la culture } \\
\text { quotidienne } \\
\circ \text { le cultivé } \longrightarrow \text { la culture savante }\end{array}$ & $\begin{array}{l}\text { une même } \\
\text { identité } \\
\text { collective }\end{array}$ \\
\hline
\end{tabular}

On voudrait proposer une notion de culture, celle-ci est conçue à partir de toutes ces conceptions antérieurement citées. Pour construire notre proposition, on s'est s'appuyé sur les composantes les plus pertinentes de celles-ci. Voici, alors, ce qu'on propose :

Un ensemble de manifestations matérielles et spirituelles, souvent héritables et modifiables ; celles-ci sont issues d'un groupe d'individus faisant partie d'une société à un moment précis.

Il s'avère convenable d'expliquer les différents éléments que comprend cette notion. Premièrement, il faudrait dire que lorsqu'on parle de manifestations matérielles, on fait référence à ce que Taylor a nommé des « artefacts », c'est-à-dire toutes les productions nées des actions des individus et de la collectivité ; celles-ci renferment des significations et, dans la plupart des cas, deviennent des symboles d'une culture donnée. On inclut dans cet univers des manifestations matérielles telles que : les productions littéraires et musicales, la peinture, l'architecture, les vêtements, la cuisine, etc.

Par contre, les manifestations spirituelles comprennent tout ce que fait référence aux mentalités, croyances, valeurs, modes d'agir ou comportements partagés par les membres d'un groupe social. La fusion de tous ces éléments sont à la base, comme l'a formulé Geertz, de la création de normes, codes, etc. qui régissent une société quelconque. 
Tous ces éléments ainsi que les « significations culturelles $»^{21}$ qu'ils portent sont, usuellement, hérités d'une génération à l'autre. Cette transmission se fait de manière tacite, comme quelque chose qui va de soi ou complètement explicite, par exemple pour préserver quelques traits particuliers de la culture.

En ce qui concerne l'héritabilité de ces manifestations, on a décidé d'employer le terme souvent car, il est de tous connu que dans toutes les cultures, il y a des expressions culturelles qui se perdent, qui ne sont pas transmises ou qui sont dépossédées de leur signification et deviennent peu importantes.

Néanmoins, il existe d'autres manifestations culturelles qui sont transformées à cause d'un changement générationnel, des mentalités ou par l'influence des expressions culturelles étrangères, ceci grâce à la mobilité des individus, caractéristique de notre époque et à l'importance des médias dans les sociétés actuelles. Ceci explique le caractère dynamique qu'on a voulu donner à la culture.

Ces manifestations culturelles sont le produit d'un ensemble d'individus et de la vie en commun de ceux-ci. Ces expressions révèlent, aussi, la pensée et l'expérience collective de ce groupe. Ce groupe faisant partie d'une société comme tant d'autres constituent ce que L. Porcher ${ }^{22}$ appelle la culture nationale qui est composé d'éléments communs à tous ces groupes, ceux-ci sont appelés subcultures ou cultures sectorielles; elles présentent des traits spécifiques qui les différencient d'autres groupes et leur donnent leur originalité. Parfois, il existe des conflits entre les groupes et il y a également certains qui ont tendance à s'imposer.

Comme on vient de le dire, ces groupes ou cultures sectorielles, comme les appelle Jean-Claude Beacco ${ }^{23}$, comprennent une culture nationale déterminée. Lorsqu'on parle de cultures sectorielles ou

21 Par ce terme, on va entendre le sens que Michael Byram lui a accordé : «... un sens de ce qui est important, qui n'est pas simplement partagé, c'est-à-dire possédé par chacun mais commun, c'està-dire qui fait partie du monde de références communes. »

22 L. Porcher, La civilisation (Paris : Clé International, 1986) 9.

23 J. C. Beacco, Les dimensions culturelles des enseignements de langue (Paris : Hachette, 2000) 27. 
subcultures, on se réfêre, par exemple, à : culture bourgeoise - culture populaire, culture urbaine - culture rurale, culture cultivée - culture de masse, etc. D'après ce fait, on peut affirmer que toute culture nationale présente « un multiculturalisme », comme l'a nommé le sociologue français Louis Porcher ${ }^{24}$ qui est propre et caractéristique de celle-ci et dans lequel se trouvent la richesse et la diversité d'une culture donnée.

À propos de cultures sectorielles, Porcher propose, à partir des analyses sociologiques et anthropologiques, comme éléments distinctifs de celles-ci : le sexe, l'âge, la profession, le niveau de scolarité, l'appartenance religieuse etl'appartenance régionale.

Pourquoi a-t-on voulu faire remarquer ce point de culture nationale - subcultures ? Parce que si l'on parle de culture nationale, on se limiterait à l'étude ou à l'analyse des éléments communs aux différents groupes qui composent une société et ces éléments peuvent être peu nombreux et on risque, par exemple, dans l'enseignement d'une culture étrangère, de donner une image restreinte et simple de celle-ci, en laissant de côté les aspects, peut-être, les plus importants et intéressants.

Même si on propose une définition de culture nationale, on a, aussi, signalé dans notre notion l'importance des groupes à l'intérieur d'une société et leur rôle dans l'étude d'une culture car c'est dans ces groupes qu'on trouve la pluralité d'une culture.

\section{Approches de l'enseignement de la culture}

Il est évident depuis plusieurs décennies, l'importance de l'étude de la culture des pays de la langue cible ; mais ce qui n'a jamais été si évident, même dans les dernières années, est sous quelle approche on doit développer l'étude de la culture étrangère.

Dans l'éventail d'approches proposées et mises en pratique depuis longtemps, on peut mentionner l'approche descriptive, l'approche thématique, l'approche explicative, l'approche subjective et 
bien sûr, l'approche interculturelle en vogue et en développement depuis plus de trente ans. Cette gamme met en évidence les difficultés de choix au moment d'étudier une culture, les polémiques sur la mise en place d'une ou d'autre approche et sur l'adéquation de celles-ci pour étudier une culture dans une classe de langue étrangère.

Lorsqu'on est face à une culture autre, lors de l'enseignement d'une langue, voire dans d'autres situations, une perception de la différence surgit et d'après le linguiste français Patrick Charaudeau, celle-ci constitue « la preuve de sa propre identité $»^{25}$ et il ajoute «il est différent de moi, donc j'existe. » Il faut corriger légèrement Descartes et dire « je pense différemment, donc je suis. ${ }^{26} \mathrm{C}^{\prime}$ est-à-dire, les différences établies entre soi et les autres constituent un aspect fondamental de l'identité propre, ce sont ces différences avec les autres qui assurent en quelque sorte celle-ci. Cette perception de la différence se manifeste à travers une attraction envers la culture autre, une curiosité pour découvrir ou connaître ce qui est distinct, toutefois elle pourrait se révéler aussi à travers la peur, qui peut surgir en même temps que l'attirance, une peur envers le différent, de mettre en risque l'identité propre mais aussi de faire face à l'étranger.

Ces deux manifestations de la différence peuvent mener quelqu'un à l'acceptation réelle de l'autre mais aussi à considérer l'autre comme une menace. C'est pour cette raison que dans la plupart des cas la rencontre avec l'étranger est souvent accompagnée d'un jugement négatif ; parfois ce jugement se propage et devient ce qu'on désigne communément comme stéréotype ou préjugé.

Pourquoi avons-nous voulu présenter ces situations qui se produisent lorsqu'on se met en contact avec l'autre ? Simplement, pour faire remarquer la complexité qui caractérise le contact avec l'autre ainsi que pour montrer les difficultés qui se présentent aux enseignants, aux formateurs et aux auteurs de manuels pour guider leurtâche.

25 P. Charaudeau, «L'interculturel une histoire de fou », Dialogues et cultures 32 (Paris : FIPF, 1988) 89.

26 Charaudeau, 89. 
L'approche qu'on choisit devrait, en principe, canaliser toutes ces situations, qui apparaissent comme une sorte de choc lorsque deux cultures se rencontrent pour aboutir à un objectif primordial de l'enseignement d'une culture non maternelle : la connaissance et la compréhension de l'autre. L'approche la plus traditionnelle estl'approche descriptive. Durant de longues périodes, une démarche descriptive inspirée de cette approche a dominé l'enseignement de la culture étrangère. Pour certains spécialistes, toute étude d'une culture autre doit faire d'abord à un passage obligé par cette approche. Celle-ci construit sa démarche à partir de la description des marques caractérisant un ensemble particulier d'individus.

Cette approche doit servir, comme une sorte de guide du processus d'enseignement. On trouve valable cette idée, de même que le fait que l'approche descriptive doit être considérée comme le fournisseur des bases théoriques de l'enseignement d'une culture au moins dans un premier état de celui-ci. Cependant, rester dans cette approche serait fomenter un enseignement de type encyclopédique et bien sûr insuffisant car on se limiterait à travailler au niveau de l'acquisition de connaissances; en plus « l'étude des nœuds conflictuels, qui ne fait pas partie de l'approche descriptive, rendrait mieux compte du fonctionnement des implicites culturels dans une société qu'une information panoramique qui ne peut jamais être exhaustive. Également, la prise en compte des paramètres tels que la gestuelle et la proxémique dans l'acte de communication permet d'affiner la description des phénomènes culturels $»{ }^{27}$ [Nous avons ajouté l'italique] C'est-à-dire, même si l'approche descriptive prétend fournir une information globale de la culture cible, cette approche, conçue dès une perspective assez traditionnelle de l'enseignement de la culture, ne comprend pas d'éléments culturels essentiels pour la communication avec l'étranger et la compréhension de celui-ci.

27 G. Zarate, « Du dialogue des cultures à la démarche interculturelle », Le français dans le monde 170 (Paris : Clé International, juillet 1982) 32. 
Liée à cette approche se positionne l'approche thématique, elle propose une présentation de la culture étrangère à partir de divers thèmes rapportés à l'histoire, à la géographie, à l'économie, à la littérature, etc.

Comme l'approche descriptive, l'approche thématique cherche à proportionner aux apprenants une vision générale de la culture, insuffisante du point de vue de nouvelles théories de l'enseignement de la culture, et ne dépasse pas le niveau informatif.

Une autre approche mise en œuvre, depuis longtemps, dans la classe de langue lorsqu'il s'agit de la culture, c'est l'approche contrastive, appelée par divers spécialistes comparative et par d'autres, surtout par ceux qui trouvent la considèrent trop négative, comparatiste. Habituellement, l'approche contrastive a mené au simple établissement de différences et ressemblances entre la culture maternelle et la culture étrangère par rapport à un thème déterminé (par exemple, comparer la composition ethnique du Costa Rica et de la France). Cette approche est encore utilisée pour développer un cours de culture, elle continue à être vue comme une des approches les plus appropriées pour ceci. En revanche, la démarche contrastive est mise en question par d'autres qui ne la trouvent pas très utile, surtout quand on suppose que l'objectif de l'enseignement de la culture est la compréhension de l'autre plutôt que l'acquisition de savoirs.

Malgré les polémiques entre ceux qui défendent cette approche et ceux qui la censurent, les inconvénients que son application suscitedans la classe, il devient parfois très difficile d'éviter la comparaison entre les cultures, même si l'enseignant ne décide pas de travailler avec une démarche comparative, car lorsqu'on entre en contact avec une culture différente, on est presque immédiatement confronté à la culture maternelle. Cela parce que, comme on l'a déjà mentionné, l'étude d'une culture autre conduit à une réflexion ou, au moins à un approchement de la culture propre ; en outre, on essaie de formuler des conclusions ponctuelles et absolutistes ; par exemple, concernant l'économie, notre pays est supérieur au Togo ou le contraire. 
Ces conclusions erronées et réductrices se présentent à cause d'une analyse superficielle qui ne se préoccupe pas pour chercher l'origine et les causes de ces différences ou des ces ressemblances, ce qui pourrait être très efficace pour faciliter une compréhension de l'autre et un approchement de celui-ci.

Travailler la comparaison comme ligne d'analyse comporte le risque d'établir une hiérarchisation des cultures, une situation très courante depuis quelques siècles ; par exemple, autrefois, les cultures européennes étaient considérées supérieures à toutes les autres par rapport à une série de facteurs qui n'est pas important de citer ici ; à nos jours, certains parlent dela supériorité culturelle des pays occidentaux sur les pays d'Orient.

En outre, dans le cadre d'une approche privilégiant la comparaison, le réseau de significations qui composent les objets culturels se perd, ceci peut diriger l'étude de la culture vers un réductionnisme et une schématisation de celle-ci. On ne peut pas oublier que « chercher à établir un parallèle, vouloir retrouver dans chaque culture les mêmes éléments mais sous des formes différentes ou des degrés de maturité différente implique la croyance en l'existence d'un schéma culturel universel à partir duquel s'ordonneraient toutes les cultures. $»^{28}$

Si l'enseignant prend la décision de développer une classe à partir de l'approche contrastive, lui, en tant que médiateur culturel, devra être conscient des dangers de la comparaison et de bien conduire la classe pour éviter des conclusions émanées d'une analyse superficielle.

Comme une sorte de contrepoids aux approches descriptive, thématique et contrastive, des spécialistes (R. Galisson, L. Porcher et P. Dumont dans les années 1980) proposent de travailler la culture étrangère à partir d'une approche subjective qui se fonde sur trois lignes directrices, à savoir:

28 M. Abdallah-Pretceille, «La perception de l'autre », Le français dans le monde 181 (Paris : Clé International, nov.-déc. 1983) 41. 
- une pratique d'observation personnelle de la part de l'apprenant dela culture cible dans le but qu'il construise ses propres représentations de celle-ci sans l'influence d'informations préalables.

- $\quad$ une adoption de positions de critique et de découverte de la culture à partir de différents supports d'un même thème.

- un placement de l'apprenant dans des situations qui le mènent à une interprétation et à une compréhension des comportements de membres de la culture cible et d'autres où il devra se comporter en tant qu'être social dans des interactions.

Selon le linguiste Pierre Dumont ${ }^{29}$ et appuyé sur les réflexions de Galisson, c'est dans ce dernier aspect que l'union existante entre enseignement-apprentissage culturel et langagier se fait plus évidente. Pour Galisson ${ }^{30}$, il existe une charge culturelle partagée dans les mots qui est difficile à légitimer et à enseigner car, d'après lui, elle régit les attitudes, les comportements, les représentations et les coutumes des natifs de la culture cible, même si ceux-ci ne le savent pas. Ce rapport entre langue et charge culturelle partagée est appelé par Galisson identité collective. Pour lui, ces deux éléments composent un « identificateur » pour tous les individus qui conforment un groupe social donné.

Une classe de culture dans le cadre d'une approche subjective et à partir de la charge culturelle, constituerait à se situer dans la voie de l'acquisition d'une culture comportementale, un moyen pour comprendre les autres et être compris ; cette culture est « liée au vécu quotidien des locuteurs bien plus que d'une encyclopédique caractéristique de la culture cultivée. $\gg^{31} \mathrm{La}$ mise en pratique de ce type d'approche résulte un peu difficile car, dans l'actualité ce que Dumont appelle la culture minimale partagée ne fait pas partie, au moins très claire, des programmes de culture. Cependant, elle pourrait être

29 P.Dumont, L'interculturel dans l'espace francophone (Paris : L'Harmattan, 2000) 193.

30 Galisson, 84.

31 Dumont, 193. 
travaillée dans les classes au moyen d'une étude réflexive des mots ou des expressions puisqu'ils sont porteurs d'une signification culturelle commune aux membres d'une société.

Même si cette approche n'est très connue ni encore très développée, l'application de celle-ci dans un cours de culture serait très profitable surtout au milieu universitaire où les apprenants ont un niveau avancé de langue (dans le cas du Costa Rica) car ceci contribuerait à l'analyse et à la réflexion qu'implique le travail dans le cadre d'une telle approche.

\section{L'approche interculturelle}

Les années 1970-1980 sont marquées par les valeurs de la consommation excessive, l'individualisme, le néolibéralisme et les déplacements migratoires, entre autres phénomènes sociaux et économiques. En matière de didactique des langues, de grands changements se produisaient dans le but de renouveler cette discipline. En ce qui concerne l'étude de la culture en classe de langue étrangère, des visions réformatrices ont surgi pour proposer de nouvelles stratégies pour aborder le fait culturel. C'est ainsi qu'est apparue avec force l'approche interculturelle, étant donné que les méthodologies appliquées jusqu'à cette époque-là, quoiqu'intéressantes et utiles, ne permettaient pas d'atteindre une vraie connaissance et compréhension de l'autre.

Le concept d'interculturel est relativement récent (un peu plus de trente ans) et de manière simplifiée, on pourrait le définir comme un processus dynamique d'échanges entre cultures différentes. L'étude de l'autre sous la perspective interculturelle implique, alors, l'acceptation de la diversité de points de vue, de regards, de comportements, et d'espaces. Étant donné ceci, l'interculturel « n’est pas un contenu d'enseignement, mais plutôt une démarche qui vise, la construction de passerelles, de liens entre les cultures. $»^{32}$

32 R. M. Chaves, L. Fovier et S. Pélissier, L'interculturel en classe (Paris : Presse universitaire de Grenoble, 2012) 12. 
L'interculturel propose non seulement une étude d'altérité mais une réflexion sur la culture propre, une reconstruction permanente de l'identité dans le cadre d'une relation avec l'autre. C'est pourquoi cette perspective d'approche part du fait que l'ethnocentrisme empêche le travail sur la culture cible et qu'il est nécessaire d'éliminer cette barrière pour arriver à un état de reconnaissance et d'acceptation de l'autre et de la différence, une différence qui n'implique pas la supériorité ou l'infériorité d'une culture par rapport à l'autre.

Le travail sur la culture cible dans le cadre de l'approche interculturelle suppose le dépassement de l'étude de documents et la simple compréhension de textes. Cette démarche exige la mise en place d'une étude qui favorise l'acquisition d'une compétence facilitant la résolution des difficultés rapportées au contact avec l'autre et à la découverte de son identité et des pratiques et des comportements, jusqu'à présent évidents, liés à la culture propre. Cette compétence est conçue comme la prise de conscience de notre propre existence (notre environnement, nos sentiments et nos pensées) et, en plus, elle comporte la connaissance et la compréhension de l'autre comme des éléments essentiels pour accepter et respecter les différences culturelles.

On ne peut pas oublier qu'aborder une culture étrangère sous l'approche interculturelle place l'autre au centre des relations et promeut une mise en question incessante des préjugés et une ouverture envers ce qui est inconnu et incompris. C'est pourquoi, dans une classe de FLE, il serait utile de conscientiser les étudiants au rôle qui jouent les stéréotypes et l'importance de les éliminer. En outre, il faudrait travailler les pratiques culturelles fondamentales de la vie quotidienne (par exemple : la famille, l'alimentation, les croyances, l'habitat) et les rituels de communication ; ceci, entre autres aspects, faciliterait l'étude sur l'autre.

L'approche interculturelle constitue, alors, dans le contexte actuel, un excellent guide de principes et méthodologies pour promouvoir et développer les capacités d'intercommunication, interaction et intercompréhension entre les cultures différentes. 


\section{Le rôle de l'enseignant dans l'étude de la culture}

L'enseignant joue un rôle important dans l'étude de la culture ; les représentations que l'apprenant puisse se faire de la culture étrangère sont en rapport étroit avec sa position comme transmetteur de connaissances et à la position assumée par une institution déterminée.

Un enseignant natif ne porte pas la même vision de la langue et de la culture qu'un professeur qui enseigne une langue et une culture, pour lui-même, étrangères. Dans notre pays, on ne compte pas, dans les universités, avec un grand nombre d'enseignants ressortissants d'un pays francophone, ce qui n'en est pas de même pour certaines institutions qui engagent des professeurs natifs pour faire les cours de langue et culture ; dans ces cas, on peut être face à une découverte spontanée de la culture ; c'est-à-dire, insérée dans un processus sans une progression systématique permettant de donner un développement cohérent au cours en question et qu'en plus risque de ne représenter qu'une transmission des valeurs étrangères.

Ce type d'approche pourrait, également, porter un regard subjectif sur l'enseignement puisqu'il ne s'agit pas d'une exposition de la culture dans son propre milieu. Cette subjectivité, provenant du choix de l'individu et de son regard sur soi, s'étend au choix des contenus à développer et aux respectives réflexions portées en classe, ainsi qu'aux valorisations faites des phénomènes culturels. Tout cela dû au fait que toute culture est de l'ordre du normal, autrement dit, la culture maternelle va toujours être évidente pour l'individu qui en fait partie, c'est pourquoi, le regard du sociologue -supposé objectifjoue un rôle prépondérant dans le processus d'enseignement d'une culture étrangère.

Bref, les professeurs natifs risquent de porter une image subjective de la langue et de la culture, ceci dépend de leur idéologie, ainsi que de leur conception de la langue et de l'enseignement. C'est pour cette raison que tout enseignant (natif ou non), en tant 
que médiateur interculturel, doit compter avec une formation lui permettant de transmettre objectivement la culture et non seulement se contenter de faire une description de l'autre, ce qui n'est pas du tout correct.

De cette manière, nous avons fait un parcours théorique à travers les domaines essentiels qui interviennent dans le phénomène de l'enseignement-apprentissage d'une culture étrangère. Ces éléments sont nécessaires pour fournir une explication de la complexité de l'étude de l'autre. C'est pourquoi on veut montrer la nécessité de la construction d'une démarche différente à celle mise en pratique depuis longtemps, une démarche appuyée sur une base théorique qui favorise la connaissance et la compréhension de l'autre.

\section{Principes de l'étude de la culture autre}

La proposition d'étude des faits culturels qu'on propose, est basée sur des notions théoriques qui s'avèrent indispensables lors du contact avec l'autre. Les principes de l'interculturel et de l'altérité, entre autres, constituent les piliers sur lesquels se soutient notre proposition car ceux-ci permettent de définir la démarche à suivre, les approches à mettre en pratique et les supports à utiliser. En mettant l'accent sur ces principes, on remarque, à nouveau, l'importance de mener l'apprenant à la compréhension de l'autre, à la réflexion sur son propre système de valeurs, à la valorisation de l'autre dans sa propre quotidienneté et à l'élimination ou, au moins, à une atténuation de certains stéréotypes et de l'ethnocentrisme, deux éléments qui surgissent lors du contact entre deux groupes de manière directe, voire de manière indirecte, au moyen des articles de presse, chansons, films et d'autres supports

Ces principes nous tracent les objectifs de la démarche d'étude, à savoir: 
- Déterminer un ensemble thématique cohérent qui permette d'étudier, d'analyser et de comprendre l'autre dans sa propre réalité

- Utiliser les différentes sources d'information sur le contexte français et francophone disponible pour mener à bien une étude approfondie de l'autre

- Identifier les stéréotypes et les représentations présents dans un document quelconque

- Identifier les sources de disfonctionnement culturel

- Identifier les implicites culturels

\section{Démarche d'approche de la culture}

Les contenus proposés sont étudiés à partir des approches créées par Francis Debyser $(1981)^{33}$, celles-ci sont centrées sur la société (approche sociologique), sur l'individu (approche anthropologique) et sur la signification des faits culturels (approche sémiologique). Chaque thème peut être traité d'un point de vue distinct soit sociologique, soit anthropologique soit sémiologique ; cela dépend des objectifs à atteindre dans chaque activité.

L'approche sociologique consiste à considérer la culture comme une manifestation sociale. Elle fournit les informations de base pour l'étude d'une culture quelconque ; par exemple, les statistiques et les données sociales, économiques et politiques ; ainsi que la dimension générale d'un fait et ses relations avec la société. Les documents les plus utilisés pour travailler dans une perspective sociologique sont : les chiffres, les enquêtes et les informations de la presse, c'est-à-dire des données, en principe, objectives.

Les propositions pédagogiques doivent tenir compte de l'approche sociologique pour aborder et favoriser la compréhension des éléments de réflexion qui déterminent la dynamique sociale,tels que:

33 F. Debyser, Mours et mythes (Paris: Hachette, 1981) 9-21. 
- la place qu'occupent certains faits comme la politique, le sport ou les loisirs dans la société française ou francophone

- le rapport existant entre les gens et ces faits, selon les groupes sociaux ou le sexe

- l'image que possède un groupe social d'un autre

- $\quad$ études au moyen des enquêtes, etc.

En ce qui concerne l'approche anthropologique, elle se centre d'avantage sur les individus que sur le groupe. À travers cette approche, on pourra aborder et même comprendre les réalités quotidiennes, le vécu, les habitudes et les attitudes des Français ou d'autres francophones. En plus, cette approche favorise la décentration de la personne et l'objectivation tant de la culture maternelle que de l'étrangère car, grâce à l'étude de l'autre, l'apprenant peut évaluer la pertinence de certaines idées fixées à propos de l'autre et de son propre groupe. Les supports utilisables pour étudier la culture dès la perspective anthropologique sont : des articles de presse, des témoignages, des interviews, entre autres.

Les exercices qu'on propose sous l'angle de l'approche anthropologique doivent:

- déterminer les impressions et les attitudes des individus envers d'autres, envers leur pays et eux-mêmes.

- $\quad$ préciser la place de certains phénomènes ou pratiques dans la vie des Français, d'autres Francophones ou des Costariciens.

Quant à l'approche sémiologique, elle favorise une étude de la culture étrangère à travers une démarche qui cherche à identifier les indices culturels implicites ou explicites; puis, à les regrouper et finalement, à les interpréter. Cette démarche aidera à la compréhension de la culture autre. En plus, l'analyse et la réflexion, auxquelles mène l'approche sémiologique, contribueront à faire émerger les 
représentations, les stéréotypes ou les préjugés qu'un groupe a d'un autre ou de soi-même.

Avec l'approche sémiologique, on propose de:

- identifier et analyser les éléments porteurs de connotations culturelles

- dégager la signification culturelle de divers faits et signes.

- interpréter des phrases ou des mots qui véhiculent des indices culturels

Également, on propose un travail centré sur la culture francophone et non seulement sur la culture française, ceci dans l'intention de montrer la diversité culturelle que représente la francophonie. L'application pédagogique de différents axes thématiques, composant les modules qu'on propose (voir plus bas) est conçue dans le cadre de l'approche interculturelle, défini comme le travail sur la culture autre qui renvoie à une étude sur la propre identité et sur la reconnaissance de l'autre comme sujet et qui favorise la solidarité et la chute de barrières entre les peuples. Cette application est aussi appuyée sur un des éléments les plus importants de l'interculturel : l'altérité. Sous cette perspective, on privilégie la compréhension de l'autre comme objectif primordial même si l'acquisition de connaissances n'est pas négligeable.

Il est bien connu que la construction de la compétence culturelle «passe par une transformation des attitudes, des représentations initiales de l'étranger $» \cdot{ }^{34} \mathrm{C}$ 'est pourquoi on espère que l'étudiant sera capable d'interpréter les différences, de mettre en relation des systèmes différents et de gérer les conflits caractéristiques de la communication interculturelle. On prétend, alors, s'approcher de la culture francophone à partir d'une réflexion et d'une analyse des

34 M. Byram et G. Zarate, « Définitions, objectifs et évaluation de la compétence socioculturelle », dans « Apprentissages et usage des langues dans le cadre européen », Le français dans le monde, numéro spécial (Paris : Clé International, juillet 1998) 75. 
faits culturels qui mènent à la compréhension et à la reconnaissance de l'étranger et à la relativisation de ces faits dans leur réalité.

La démarche pédagogique d'approche des faits culturels qu'on suggère a été élaborée à partir des axes fondamentaux tels que l'altérité, l'interculturel, les stéréotypes, les représentations et notre notion de culture ; ce qui permet l'élaboration d'un matériel construit à partir d'une base théorique solide qui légitime la nécessité, l'intérêt et le caractère rénovateur de cette proposition.

Cette démarche suit une structure ; à savoir, des activités préparatoires, une exploitation pédagogique du support choisi, des activités pour réagir ou relier les connaissances et finalement des activités complémentaires pour élargir ou compléter le thème abordé. Cette organisation assume une progression dans l'étude et l'analyse des contenus selon les approches mentionnées antérieurement. L'organisation de la démarche spécifique de travail sur les documents authentiques, en tant que supports, considère les propositions pour une lecture interactive de Francine Cicurel ${ }^{35}$ dans la mesure où les étapes proposées favorisent l'articulation des principes théoriques fondamentaux de l'étude d'une culture autre.

\section{Les ensembles de contenus}

Il faudrait dire qu'il serait important d'établir, d'abord, une série de modules permettant d'aborder de manière cohérente la culture autre. À titre d'exemple, on présente une proposition de cursus de culture étrangère dans le cadre du FLE. En plus, le choix des axes thématiques pour établir ces modules de contenus correspond aux besoins et manques des étudiants et des enseignants. On parle de besoins et manques en ce qui concerne les contenus et le traitement de ceux-ci dans un cursus de culture francophone plutôt que de culture française et les approches utilisées pour aborder la culture en classe de langue étrangère. 
Deuxièmement, on voudrait remarquer que cet ensemble d'unités comporte quelques éléments qui sont censés caractériser une culture quelconque et pouvant être définis comme des objets du culturel. Du point de vue théorique, le choix des contenus se soutient sur les notions fournies par Galisson ${ }^{36}$ de culture quotidienne et de culture cultivée. Par rapport à la culture quotidienne ou culture comportementale, on propose comme contenus à travailler le comportement non verbal et le comportement verbal.

À l'égard de la culture cultivée ou culture savante, on présente certains thèmes liés à l'histoire ou à la géographie, cependant ceux-ci ne devraient pas être traités de manière traditionnelle, c'est-à-dire, à partir d'une approche qui limite l'enseignement à la description de la culture.

En outre, la construction de ces modules s'appuie sur les propositions de l'historien Pierre Nora $^{37}$, de traiter certains aspects qui sont presque obligatoires, comme ce qu'il appelle les « lieux de mémoire » (module 1) tels que les symboles nationaux d'un pays.

D'autres contenus de ces modules répondent à ce qu'on appelle « les emblèmes ». Ceux-ci se présentent sous deux formes ; des traits marquants d'une culture (caractéristiques socioculturelles des Français ou d'autres peuples francophones) ; par exemple, les Français et leur rapport contradictoire avec l'État. Également, ils peuvent être la source de stéréotypes qui, en général, dévalorisent une culture (le regard de l'autre, la perception de l'autre, le regard de soi-même) (module 3).

En ce qui concerne le moduleII, il prétend développer une étude, non exhaustive, des rapports que les membres d'un groupe entretiennent avec le travail ou la politique, par exemple. En plus, ces contenus sont liés aux comportements propres de la vie quotidienne : participer dans la vie politique, faire du sport, travailler, se distraire, entre autres. Le module III fait référence à ce que R. Galisson a appelé « la culture comportementale ».

36 Galisson, 83-87.

37 P. Nora, Les lieux de mémoires (Paris : Éd. Gallimard, 1984). 
Les contenus faisant partie des modules I et II ainsi que les contenus « $\mathrm{c}$ » et « $\mathrm{d}$ » du module III correspondent à ce qu'on nomme objets du culturel et les contenus $« \mathrm{a} »$ et $« \mathrm{~b} »$ du module III correspondent aux objets de l'interculturel. Voici, alors, l'exemple de modules:

\section{Module I \\ «Lieux de mémoire»}
a) Les Français
b) La langue
c) Les habitudes alimentaires
d) Personnages célèbres de la francophonie
e) Les symboles

Module II

« L'homme en société »
a) La politique
b) Le sport
c) Le travail
d) L'économie

Module III

«Culture comportementale»

a) Le regard de l'autre

b) Le regard de soi-même

c) Le comportement verbal et non verbal

Il faut éclaircir un point ; bien que les objectifs soient l'élargissement des connaissances de l'autre et surtout la compréhension de celui-ci, dans nos propositions, on ne néglige pas les activités linguistiques qui contribuent à atteindre ces objectifs ; par exemple, les débats, les essais, la rédaction des portraits, entre autres. Finalement, en dépit des contenus qu'on suggère, on ne cherche à être ni 
exhaustif ni absolu; le choix qu'on a fait est simplement représentatif d'un éventail de possibilités.

\section{Les supports}

Divers documents authentiques, la plupart des articles de presse pris de journaux et revues francophones et des sites sur l'Internet, peuvent être utilisés comme des sources d'information sur la réalité culturelle de l'autre. Il faut aussi mentionner les textes de chansons, des vidéos et des bandes dessinées, entre autres, qui fonctionnent comme des supports pour l'étude de la culture.

On sait que les documents authentiques sont des moyens pour s'approcher de la réalité de l'autre et qu'ils véhiculent, non seulement la pensée de l'auteur, mais celle d'une société, même si ceux-ci n'ont été conçus ni pour étudier une culture ni pour être utilisés dans une classe de FLE. D'ailleurs, il faut mentionner que la variété de supports écrits et audiovisuels doit correspondre à la réalité et aux besoins de notre époque et adaptables à la réalité socio-économique de notre milieu.

\section{En guise de conclusion}

Le contexte social, politique et économique actuel au niveau national et international, la place prépondérante des médias dans la vie quotidienne et l'expansion de l'enseignement des langues étrangères favorisent le contact, à des degrés différents, avec l'autre, et toute rencontre avec l'étranger est susceptible de produire des situations de conflit.

La classe de FLE est aussi un espace où ces situations conflictuelles peuvent apparaître, c'est pourquoi l'étude de la culture de l'autre est essentielle pour éviter ou, au moins, atténuer ces conflits.

En effet, le travail de revendication de la place de la culture dans le processus d'enseignement-apprentissage d'une langue 
étrangère doit être constamment renforcé et validé car la culture est indissoluble de l'acquisition d'une langue. On propose une démarche d'analyse de faits culturels qui permet à l'apprenant de confronter sa propre réalité avec celle de l'autre, de comprendre celui-ci dans sa vie quotidienne et de réfléchir sur son propre système de valeurs culturelles; de cette manière les principes fondateurs de l'approche interculturelle sont mis en relief.

L'étude systématique de la culture doit aboutir à l'acquisition d'une compétence culturelle, c'est pour cette raison qu'elle doit être en accord aux besoins et attentes des étudiants. En outre, cette étude doit permettre de se débarrasser des stéréotypes sur les autres et sur soi-même. Nous prônons un regard analytique et objectif de la culture propre car on ne doit pas oublier que pour bien comprendre l'autre, il est nécessaire de passer par la compréhension du groupe d'appartenance.

Notre proposition aspire aussi à être un déclencheur d'un travail qui débute chez nous et qui devrait s'intensifier dans les prochaines années puisque notre époque est marquée par la poussée de l'extrémisme, la renaissance dangereuse du racisme et par l'accentuation, de la part de certains de groupes, des différences entre les peuples. C'est pourquoi, la classe de langue devient un espace très approprié pour fomenter l'intercompréhension, la tolérance et la solidarité entre les peuples, dans notre cas, les Costariciens et les Francophones.

Finalement, on voudrait ajouter que se donner à la tâche de travailler et étudier une culture autre, contribue à dépasser l'évident et se questionner sur la nécessité d'accepter les différences, de relativiser les faits dans leur propre réalité et d'accepter que l'isolement et les préjugés envers les autres comme stratégie pour protéger l'identité n'a jamais fonctionné et par contre, elle a été la cause des conflits. 